\title{
PENGARUH INTELLECTUAL CAPITAL DAN CORPORATE SOCIAL RESPONSIBILITY DISCLOSURE TERHADAP KINERJA PERUSAHAAN
}

\author{
Chintya \\ Melinda Haryanto \\ Universitas Pelita Harapan \\ melinda.haryanto@uph.edu
}

\begin{abstract}
The purpose of th is study was to test empirically the influence of Intellectual Capital and Corporate Sociall Responsibility Disclosure to the performance of companies in Indonesia. Intellectual capital is measured using Pulic method (VAIC) and Corporate Social Responsibility Disclosure measured by using CSDI (CSR Index). Company performance is proxied with company profitability that is measured by Return on Assets. Data used in this study is secondary data, consist of annual reports, financial reports, and sustainability reports. The sample used in this study was chosen by using purposive sampling method with the aim to get the sample according to the criteria. The sample in this study amounted to 76, which consisted of 19 manufacturing companies of the basic and chemiccal industry sectors during the period 2013 to 2016. The results showed that intellectual capital and corporate social responsibility disclosure positively affect the financial performance of the company
\end{abstract}

Keyword : corporate social responsibility disclosure, intellectual capital, performance, Return on Asset

\section{PENDAHULUAN}

\subsection{Latar Belakang}

Pada era globalisasi ini, teknologi telah mengalami perkembangan yang sangat pesat dan diiringi dengan persaingan bisnis yang semakin kompetitif. Menurut Hurwitz et al (2002) dalam Faradina dan Gayatri (2016) dengan adanya perkembangan teknologi dan ilmu pengetahuan yang semakin maju serta persaingan yang semakin ketat telah merubah strategi bisnis perusahaan, dimana yang awalnya didasarkan pada tenaga kerja (labor-based business) kemudian diganti dengan bisnis yang didasarkan pada pengetahuan (knowledge based business) sehingga perusahaan tersebut dapat terus berkembang dann mempertahankan keberadaannya. Hal inilah yang menyebabkan terjadinya peningkatan yang besar pada knowledge workers dan aset tak berwujud. Perkembangan perekonomian yang mengarah kepada pengetahuan dan informasi akan menuntut perusahaan untuk mulai memperhatikan intellectual capital (Anghel, 2 008 dalam Alipour, 2012). Modal intelektual memiliki peranan yang sangat penting dalam membantu perusahaan menciptakan nilai sekaligus dalam memperoleh competitive advantage (Bollen et al, 2005 dalam Bruggen et al, 2009).

Meskipun intellectual capital berpengaruh terhadap kinerja perus ahaan, pengukuran untuk menilai modal intelektual itu sendiri tidaklah mudah. Hal ini telah mendorong Pulic untuk menilai efisiensi dari nilai tambah modal intelektual perusahaan dalam mengukur intellectual capital (value added intellectual coefficient - VAIC ${ }^{\mathrm{TM}}$ ) (Hadiwijaya dan Rohman, 2013). Gambaran terkait dengan kondisi dan kinerja perusahaan biasanya dapat diamati melalui informasi yang disaji kan pada laporan keuangan. Namun, tidaklah cukup jika hanya berfokus kepada kinerja keuangan saja karena masih ada faktor lain yang dapat mempengaruhi kinerja 
perusahaan, untuk itu perlu untuk memperhatikan nilai lebih yang dimiliki oleh perusahaan seperti knowledge capital.

Dewasa ini, perusahaaan mulai dituntut untuk dapat bertanggungjawab kepada pihak stakeholder, dimana perusahaan membangun keselarasan dengan stakeholder-nya seperti dengan melakukan program tanggung jawab sosial atau corporate social responsibilty. CSR berkaitan erat dengan bagaimana tindakan perusahaan terhadap stakeholders baik yang berada di dalam maupun di luar perusahaan. Corporate social responsibility merupakan salah satu bentuk sustainability reporting yang menyajikan informasi pada aspek sosial, lingkungan, dan keuangan perusahaan. Menurut Hadi (2009), suatu kehidupan dapat dipengaruhi oleh dampak negatif yang dihasilkan dari industrialisasi, seperti radiasi, pencemaran, dan hubungan yang tidak harmonis antara perusahaan dengan stakeholders-nya. Maka dari itu, perusahaan dituntut untuk melakukan kegiatan CSR agar dapat menjaga lingkungan dan sosial. Tidak hanya itu, perusahaan juga diwajibkan untuk melaporkan informasi mengenai aktivitas dan tanggung jawab lingkungan yang telah dilakukan agar dapat membangun hubungan yang harmonis antara perusahaan dengan lingkungannya.

UU PT No.40 Tahun 2007 pasal 74 Undang-undang Perseroan Terbatas (UUPT) yang baru menyebutkan bahwa PT yang menjalankan usahanya pada bidang yang bersangkutan dengan sumber daya alam wajib untuk melaksanakan tanggung jawab sosial dan lingkungan. Dari penjelasan diatas, dapat dilihat bahwa CSR sangat penting untuk dilakukan dan berdampak kepada masyarakat, seperti dapat menarik perhatian konsumen sehingga konsumen akan melakukan pembelian pada perusahaan yang melakukan corporate social responsibility dan hal ini akan berpengaruh terhadap laba perusahaan.

Penelitian yang dila kukan oleh Faradina dan Gayatri (2016), Prasetio (2015), Agustina, Yuniarta, dan Sinarwati (2015) dan Fatima (2012), menunjukkan bahwa terdapat pengaruh yang positif dan signifikan antara intellectual capital dengan profitabilitas perusahaan yang diukur dengan menggunakan return on assets. Sebaliknya, terdapat juga hasil penelitian yang berbeda yang dilakukan oleh Ciptaningsih (2013) dimana intellectual capital tidak berpengaruh terhadap kinerja keuangan perusahaan yang diukur dengan menggunakan ROA.

Penelitian yang dilakukan oleh Agustina, Yuniarta, dan Sinarwati (2015) menunjukkan bahwa pengungkapan corporate social responsibility berpengaruh positif terhadap kinerja keuangan perusahaan sedangkan penelitian yang dilakukan oleh Wardani (2015) dan Ermawati (2014) menunjukkan bahwa pengungkapan CSR tidak berpengaruh terhadap kinerja perusahaan.

Berdasarkan penelitian sebelumnya dimana terdapat hasil penelitian yang berbeda, maka dalam penelitian ini akan di uji kembali pengaruh intellectual capital dan corporate social responsibility disclosure terhadap kinerja perusahaan. Hasil dari penelitian yang dilakukan diharapkan dapat memberikan bukti bahwa dengan dilakukannya pemanfa atan IC dan CSRD akan memberikan nilai tambah kepada perusahaan yang dapat mengarah kepada peningkatan kinerja perusahaan dan menjadikan perusahaan lebih kompetitif.

\section{Landasan Teoritis dan Pengembangan Hipotesis 2.1. Stakeholder Theory}

Dalam teori stakeholder, dapat dilihat bahwa perusahaan bukanlah sebuah entitas yang hanya beroperasi untuk memenuhi kepentingannya sendiri saja, melainkan harus memenuhi kepentingan stakeholdernya. Salah satu kegiatan yang dilakukan perusahaan untuk memenuhi keinginan para stakeholder-nya adalah dengan melakukan kegiatan corporate social responsibility (CSR). CSR merupakan strategi perusahaan untuk memuaskan keinginan stakeholder. Menurut Goh dan Lim (2004) dalam Fadri dan Wahidahwati (2016), perusahaan juga dapat menyajikan informasi terkait dengan modal intelektual, karena informasi tersebut menunjukkan bahwa perusahaan telah mengelola modal intelektualnya sehingga terciptalah nilai 
tambah (value added) untuk perusahaan tersebut. Dengan adanya pengungkapan terkait modal intelektual, diharapkan dapat meningkatkan kepercayaan stakeholders dan mendorong para stakeholders untuk loyal terhadap produk dan jasa yang ditawarkan perusahaan.

\subsection{Teori Legitimasi}

Deegan (2014) menyata kan bahwa melalui teori legitimasi, organisasi atau perusahaan terus berusaha untuk memasti kan bahwa kegiatan yang mereka lakukan sesuai dengan bingkai dan norma yang ada dalam masyarakat atau lingkungan dan juga memastikan bahwa aktivitas yang mereka lakukan dapat diterima oleh pihak luar sebagai sesuatu yang sah. Barkemeyer (2007) menjelaskan bahwa tanggung jawab sosial perusahaan di negara berkembang jika dilihat dari sisi legitimasi organisasi meliputi kapabilitas untuk menempatkan motif dalam maksimalisasi keuntungan seehingga hal ini memberikan gambaran lebih jelas mengenai motivasi perusahaan dalam memperbesar tanggung jawab sosialnya. Dengan adanya kegiatan corporate social responsibility yang dilaksanakan oleh perusahaan menyebabkan perusahaan sudah bertindak sesuai dengan norma masyarakat sehingga dapat memperoleh legitimasi dari masyarakat.

\subsection{Modal Intelektual}

Menurut Pulic (1998), modal intelektual meliputi human, structural, dan customer capital dalam menciptakan nilai tambah. Pada tahun 1997, Pulic mengembangkan metode VAIC ${ }^{\mathrm{TM}}$ yang dapat digunakan untuk mengukur efisiensi perusahaan. $\mathrm{VAIC}^{\mathrm{TM}}$ menyajikan informasi tersebut dari aset berwujud dan aset tak berwujud yang dimiliki perusahaan dan menjadi instrumen dalam pengukuran intellectual capital. Menurut Pulic (1998), konsep penting dalam $\mathrm{VAIC}^{\mathrm{TM}}$ adalah corporate intellectual ability yang berupa efisiensi penciptaan nilai total yang disebabkan oleh penggunaan modal intelektual dan modal fisik dalam bisnis.

Koefisien $\mathrm{VAIC}^{\mathrm{TM}}$ yang semakin tinggi menunjukkan bahwa semakin banyak value yang diciptakan. Pulic menjelaskan bahwa parameter utama dari $\mathrm{VAIC}^{\mathrm{TM}}$ adalah modal intelektual dan modal fisik, dimana modal intelektual terbagi lagi menjadi dua komponen, yakni structural dan human capital. Terdapat tiga input dalam mengukur VAIC ${ }^{\mathrm{TM}}$, yakni value added human capital, structural capital value added, dan value added capital employed.

\subsection{Corporate Social Responsibility}

Berdasarkan ISO 26000 (2010), istilah tanggung jawab sosial atau corporate social responsibility (CSR) mulai digunakan sekitar tahun 1970-an meskipun beberapa aspek yang terdapat pada tanggung jawab sosial telah ada sampai akhir abad 19 dan bahkan pada periode sebelumnya. CSR mulai berkembang di Indonesia sejak diterbitkannya UU No.40 tahun 2007 mengenai Perseroan Terbatas, dimana mewajibkan perseroan yang bidang usahanya di bidang sumber daya alam untuk melaksanakan tanggung jawab sosial dan lingkungan.

CSR juga telah mengacu kepada triple bottom line dimana perusahaan harus berorientasi pada kinerja keuangan, sosial, dan lingkungan, sehingga tidak lagi hanya berorientasi kepada kinerja keuangan. Dengan mengacu kepada triple bottom line, hal ini dapat menjamin keberlanjutaan dari perusahaan tersebut. Cheng dan Christiawan (2011) menyatakan bahwa dengan melaksanakan kegiatan CSR, perusahaan akan menerima berbagai manfaat, seperti dapat meningkatkan citra perusahaan, menurunkan biaya operasi, dan meningkatkan penjualan. Saputri (2011) dalam Dela (2014) mengemukakan beberapa tujuan dari CSR, yakni agar dapat meningkatkan citra perusahaan, dimana menunjukkan bahwa perilaku yang telah dilakukan perusahaan adalah baik serta untuk me mberikan informasi kepada stakeholder.

Selain menerapkan CSR, perusahaan juga perlu melakukan pengungkapan atas kegiatan CSR yang telah dilakukan. Pengungkapan CSR memiliki peran yang besar terhadap perusahaan, seperti dapat menarik perhatian dari masyarakat. Adapun tujuan dari pengungkapan tanggung jawab sosial perusahaan menurut Gray et al (1998) dalam Wardani (2015) yakni untuk 
meningkatkan image perusahaan, meningkatkan akuntabilitas suatu organisai, serta menyajikan informasi kepada pihak lain.

Dengan adanya pengungkapan sosial dan lingkungan yang dilakukan oleh perusahaan, akan menunjukkan bahwa perusahaan tersebut memiliki kinerja yang baik dimata masyarakat, sehingga perusahaan akan memiliki citra dan pengakuan yang baik dan hal ini akan mendorong para customer untuk tetap menggunakan produk ataupun jasa yang ditawarkan oleh perusahaan yang bersangkutan. Salah satu standar yang digunakan untuk mengukur corporate sustainability report adalah pedoman dari Global Reporting Index (GRI).

\subsection{Kinerja Perusahaan}

Wibowo dan Faradiza (2014) dalam Wijayanti (2016) menjelaskan bahwa kinerja keuangan merupakan gambaran terkait dengan kondisi dan keadaan suatu perusahaan yang dapat dianalisis melalui alat analisis keuangan sehingga dapat mengetahui bagaimana kondisi keuangan dan prestasi keuangan yang dimiliki perusahaan tersebut dalam kurun waktu tertentu. Dengan dilakukannya pelaporan kinerja keuangan, maka akan membantu para pengguna laporan keuangan untuk menganalisis kondisi keuangan perusahaan masa lalu dan memprediksi keuangan dimasa datang.

Banyak sekali teknik pengukuran yang dapat dilakukan untuk mengukur kinerja perusahaan, dimana salah $\mathrm{s}$ atunya adalah mengukur dan membandi ngkan rasio. Pada penelitian ini, pengukuran kinerja perusahaan dilakukan dengan menggunakan rasio profitabilitas yang diukur dengan menggunakan return on assets (ROA). Hal ini dilakukan karena penelitian ini untuk melihat kemampuan perusahaan dalam menghasilkan laba dari pemanfaatan aset perusahaan sehingga akan lebih menunjukkan kemampuaan dari perusahaan.

\subsection{Kerangka Pemikiran dan Pengembangan Hipotesis}

Kerangka pemikiran dapat dilihat pada gambar 1. Pengaruh Intellectual Capital terhadap Return on Assets (ROA)

Kinerja keuangan sebuah perusahaan sangatlah penting, baik itu untuk digunakan oleh internal maupun eksternal perusahaan. Dengan adanya hasil yang baik dari kinerja keuangan, maka akan menunjukkan bahwa perusahaan yang bersangkutan sehat dan telah memanfaatkan sumber dayanya dengan baik sehingga memiliki hasil yang baik pula seperti memiliki laba yang tinggi akibat peningkatan dalam penjualan. Dengan adanya resource-based view, menunjukkan bahwa perusahaan tersebut telah mengelola modal intelektualnya dengan baik sehingga terciptalah value added di perusahaan tersebut. Modal intelektual yang dikelola dengan baik sangatlah berperan dalam peningkatan profitabilitas perusahaan, dimana seperti penelitian yang telah dilakukan oleh Prasetio (2015) yang menunjukkan bahwa intellectual capital berpengaruh positif terhadap kinerja keuangan perusahaan.

H1: Intellectual capital berpengaruh signifikan positif terhadap return on assets

Pengaruh Corporate Social Responsibility Disclosure terhadap Return on Assets (ROA) Dengan adanya kegiatan CSR dan pengungkapan yang dilakukan oleh sebuah perusahaan, akan memberikan value added dan keunggulan bagi perusahaan tersebut dibanding dengan perusahaan yang tidak melakukan CSR. Menurut Finch (2005), sustainability reporting framework merupakan alat yang dapat digunakan untuk mengkomunikasikan kinerja manajemen kepada para stakeholder agar dapat mencapai keuntungan jangka panjang, seperti meningkatkan kinerja keuangan dan memaksimalkan profit. Dengan demikian, kegiatan CSR diharapkan dapat memberikan dampak yang positif terhadap perusahaan seperti meningkatkan profitabilitas perusahaan. Pengukuran profitabilitas diproksikan dengan ROA. Semakin tinggi ROA yang dimiliki perusahaan, maka akan menunjukkan produktifitas aset yang semakin baik dalam memperoleh keuntungan bersih. Dengan demikian, maka diajukan hipotesis berikut ini: 
H2 : Corporate social respo nsibility disclosure berpengaruh signifikan positif terhadap return on assets

\section{METODOLOGI PENELITIAN}

\subsection{Populasi, Sampel, dan Sumber Data}

Populasi dalam penelitian ini adalah seluruh perusahaan manufaktur sektor industri dasar dan kimia yang terdaftar di Bursa Efek Indonesia (BEI) pada periode 2013-2016 serta mengungkapkan tanggung jawab sosial perusahaan dalam laporan tahunan atau sustainability report. Sampel pada penelitian ini dipilih dengan menggunakan metode purposive judgement sampling. Adapun kriteria yang digunakan dalam penentuan sampel penelitian ini adalah:

1. Sampel yang dipilih adalah perusahaan manufaktur sektor industri dasar dan kimia yang terdaftar di BEI selama tahun 2013-2016 dan menyediakan laporan tahunan lengkap termasuk annual report dan laporan keuangan selama empat tahun berturut-turut (2013, 2014, 2015, 2016)

2. Perusahaan memiliki laba dan ekuitas yang positif selama periode pengamatan.

3. Laporan keuangan perusahaan disajikan dalam mata uang Rupiah.

\subsection{Model Empiris Penelitian}

Penelitian ini menggunakan satu model utama untuk menguji hipotesis yang telah dirancang, dimana model ini akan digunakan untuk menginvestigasi hipotesa $\mathrm{H} 1$ dan $\mathrm{H} 2$

$$
\mathrm{ROA}=\beta 0+\beta 1 \mathrm{IC}+\beta 2 \mathrm{CSR}+\beta 3 \mathrm{FS}+\beta 4 \mathrm{LEV}+\beta 5 \mathrm{CI}+\varepsilon
$$

Keterangan :

$\begin{array}{lll}\mathrm{ROA} & = & \text { Return on assets } \\ \mathrm{IC} & = & \text { Intellectual capital } \\ \mathrm{CSR} & = & \text { Corporate social responsibility disclosure } \\ \mathrm{FS} & = & \text { Firm size } \\ \mathrm{LEV} & = & \text { Leverage } \\ \mathrm{CI} & = & \text { Capital intensity }\end{array}$

\section{Definisi Variabel Operasional}

Variabel independen yang digunakan dalam penelitian ini adalah intellectual capital dan pengungkapan corporate social responsibility.

\section{Intellectual Capital}

Berdasarkan Pulic, model VAIC tersusun atas tiga komponen utama yaitu value added human capital (VAHU), structural capital value added (STVA), dan value added capital employed (VACA). Namun sebelum melakukan pengukuran terhadap ketiga komponen utama tersebut, hal yang harus diukur pertama kali adalah value added karena ia merupakan dasar dalam perhitungan ketiga komponen tersebut.

a. Value Added (VA)

VA = OUTPUT - INPUT atau VA = Operating income + Labor expense atau VA

$=$ Gross Margin - selling, general, and administrative expenses + Labor expense

b. Value Added= Human Capital (VAHU)

c. Structural Capital V alue Added (STVA).

d. Value Added= Capita l Employed (VACA)

e. Value $=$ Added Intelle + ctual Capital + (VAIC) 


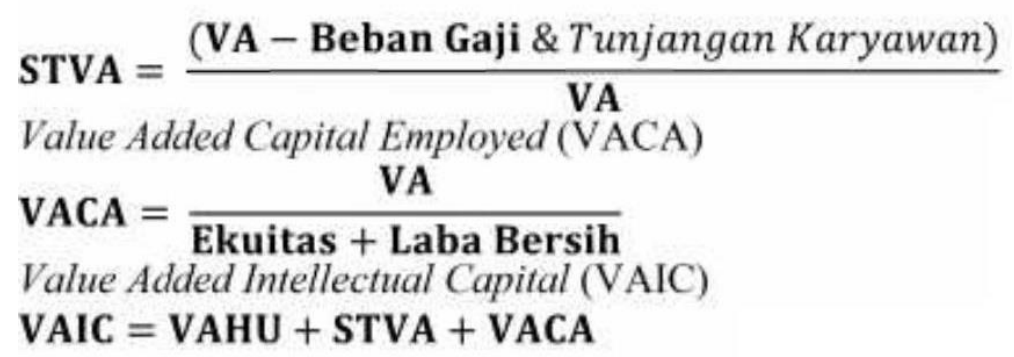

Dalam menghitung indeks CSDI, digunakanlah pendekatan dikotomi dimana akan diberikan nilai 1 jika perusahaan telah mengungkapkan item CSR, begitu juga sebaliknya jika perusahaan tidak melakukan pengungkapan maka akan diberikan nilai 0. Setelah itu, seluruh skor dari item CSR akan ditotalkan agar dapat mengetahui total keseluruhan skor perusahaan.

Berikut adalah $=\sum$ rumus CSDI :

$$
\operatorname{CSDI}=\frac{\sum X i}{n}
$$

Keterangan : CSDI $=$ Corporate social disclosure index, $\mathrm{n}=$ Jumlah item yang diharapkan $\mathrm{Xi}=(1)$ jika item i diungkapkan dan (0) jika item i tidak diungkapkan Variabel Dependen.

Variabel dependen yang digunakan dalam penelitian ini adalah return on assets, dimana merupakan proksi untuk mengukur profitabilitas perusahaan. ROA akan mengukur kemampuan sebuah perusahaan dalam memanfaatkan asetnya untuk menghasilkan profit. Nilai ROA yang semakin tinggi menunjukkän bahwa perusahaan semakin efektif dalam menghasilkan keuntungan ya ng diperoleh dari penggunaan aset secara optimal, baik itu aset berwujud maupun tidak.

$$
\mathrm{ROA}=\frac{\text { Net Income }}{\text { Total Assets }}
$$

Variabel kontrol yang digunakan adalah ukuran perusahaan, leverage, dan intensitas modal. Ukuran perusahaan diukur dengan Ln (Total Assets), leverage diukur dengan Total Liabilities dibagi Total Equities dan intensitas modal diukur dengan total assets dibagi sales revenue

\subsection{Metode Analisis dan Pengujian Hipotesis}

Pada penelitian ini, dilakukan analisis statistik deskriptif, uji asumsi klasik (uji normalitas, uji multikolinearitas dan uji heter oskedastisitas) dan uji hipotesis dengan menggunakan uji $t$ dan uji F. 


\section{HASIL DAN PEMBAHASAN}

\subsection{Hasil Penelitian}

Sampel yang digunakan pada penelitian ini adalah perusahaan manufaktur sektor industri dasar dan kimia yang terdaftar di BEI selama periode 2013-2016. Berdasarkan purposive sampling, maka jumlah sampel yang digunakan sebanyak 76. Proses pemilihan sampel dapat dilihat pada tabel 1 .

\subsubsection{Statistik Deskriptif}

Pada tabel 2 dapat dilihat bahwa ROA yang merupakan pengukuran untuk profitabilitas perusahaan memiliki nilai rata-rata sebesar $7.26 \%$ atau 0.0726 dimana menunjukkan perusahaan manufaktur sektor industri dasar dan kimia rata-rata dapat menghasilkan Rp 0,07 dari setiap Rp 1,00 aset yanng dimiliki perusahaan tersebut. Nilai tertinggi ROA sebesar 0.2607 atau $26.07 \%$ yang dimiliki oleh PT Duta Pertiwi Nusantara pada tahun 2013 sedangkan nilai terendah RO A dimiliki oleh PT Budi Starch \& Sweeteener di tahun 2015 dengan nilai sebesar 0.006 atau $0.6 \%$. Nilai maksimum VAIC sebesar 18.926 yang dimiliki oleh perusahaan Indocement Tunggal Prakarsa pada tahun 2013. Nilai minimum untuk VAIC dimiliki oleh PT Duta Pertiwi Nusantara pada tahun 2015 sebesar 2.21. Rata-rata nilai VAIC sebesar 5.524. Semen Indonesia melakukan pengungkapan CSR yang paling banyak yakni 40 item dari 91 item (43.96\%). Perusahaan dengan pengungkapan CSR yang paling sedikit dimana hanya $12.09 \%$ atau hanya 11 item yang diungkapkan dari 91 item adalah perusahaan Alkindo Naratama dan Budi Starch \& Sweetener pada tahun 2013, Kedawung Setia Industrial di tahun 2015, dan Indal Aluminium Industry di tahun 2013 dan 2014.

\subsubsection{Uji Asumsi Klasik}

Pada uji asumsi klasik, uji normalitas (tabel 3) yang dilakukan didapatkan hasil bahwa penelitian ini telah terdistribusi normal. Pada tabel 4 dapat dilihat bahwa tidak terdapat nilai koefisien korelasi antar variabel yang lebih dari 0.8 serta pada tabel 5 juga tidak terdapat nilai VIF yang lebih besar dari 10. Dengan demikian dapat ditarik kesimpulan bahwa tidak terjadi multikolinearitas diantara variabel independen . Pada tabel 6, dapat dilihat bahwa model regresi memiliki nilai probabilitas Obs*R-squared lebih besar dari 5\% dimana nilai probabilitas Obs*Rsquareds ebesar $0.5317>0.05$. Dengan demikian, dapat dikatakan bahwa model regresi memiliki kesamaan varian dari residualnya.

\subsubsection{Pengujian Hipotesis}

Hasil pengujian hipotesis yang pertama dan kedua dapat dilihat melalui tabel 7. Berikut adalah model penelitiannya : ROA $=-2.01+0.13 \mathrm{IC}+4.65 \mathrm{CSR}-0.17 \mathrm{FS}-0.22 \mathrm{LEV}-0.27 \mathrm{CI}$ $+\varepsilon$. Hasil uji $\mathrm{F}$ dapat dilihat melalui tabel 7 , dimana dengan dilakukannya uji $\mathrm{F}$ untuk menentukan apakah model penelitian layak digunakan. Hasil penelitian menunjukkan bahwa model penelitian layak digunakan. Nilai adjusted R2 pada tabel $4.9 \mathrm{~s}$ ebesar 0.6407 atau sebesar $64.07 \%$. Hal ini berarti sebesar $64.07 \%$ variasi ROA dijelaskan oleh variabel VAIC, CSR, FS, LEV, dan CI, sedangkan sisanya sebesar $35.93 \%$ dijelaskan oleh variabel lain diluar model penelitian ini. Hasil uji t dapat dilihat pada tabel 7. Koefisien VAIC bertanda positif di mana artinya VAIC berpengaruh positif terhadap ROA. Selain itu, hasil pengujian ini juga menunjukkan nilai probabilitas t-stat VAIC sebes ar 0.0000 yang dimana signifikan pada tingkat $\alpha=1 \%$. Dengan demikian, hipotesis Hal yang akan diterima dimana menunjukkan bahwa intellectual capital berpengaruh signifikan positif terhadap return on assets (ROA).

Pada tabel 7 dapat dilihat bahwa nilai probabilitas t-stat variabel CSR sebesar 0.0000 yang dimana lebih kecil dari $\alpha=1 \%$ atau signifikan pada tingkat $\alpha=1$. Variabel CSR juga memiliki koefisien yang positif yang menandakan bahwa hubungan antara kedua variabel 
tersebut adalah positif. Dengan nilai probabilitas t-stat yang lebih kecil dari tingkat $\alpha$ dimana berarti signifikan serta adanya hubungan yang positif antara CSR denga n ROA, maka H02 ditolak dan terima $\mathrm{Ha} 2$ yang berarti pengungkapan corporate social responsibility berpengaruh signifikan positif terhadap return on assets.

\subsection{Pembahasan}

Berdasarkan hasil darii hipotesis pertama, intellectual capital berpengaruh signifikan positif terhadap return on assets (ROA). Hasil uji hipotesis ini sejalan dengan hasil penelitian sebelumnya mengenai pengaruh modal intelektual terhadap kinerja perusahaan, seperti penelitian yang telah dilakukan oleh Faradina dan Gayatri (2016), Agus tina, Yuniarta, dan Sinarwati (2015), Prasetio (2015), Gozali dan Hatane (2014), serta Fatiima (2012) dimana modal intelektual berpengaruh signifikan positif terhadap kinerja perusaha an. Teori yang telah dipaparkan juga mendukung hasil dari hipotesis ini dimana berdasarkan teori resource based view bahwa sumber daya yang dimiliki perusahaan dapat membantu perusahaan dalam mencapai keuntungan kompetitif serta kinerja yang unggul. Dari hasil penelitian, dengan adanya hubungan yang positif antara modal intelektual dengan kinerja perusahaan, hal ini menandakan apabila sumber daya yang dimiliki perusahaan meningkat maka kinerja perusahaan akan menjadi semakin baik sehingga memberikan keuntungan kepada perusahaan.

Berdasarkan Pulic (1998), modal intelektual terdiri atas karyawan, organisasi, serta kemampuan yang dapat memberikan nilai tambah kepada perusahaan. Hasil pengujian hipotesis pertama yang menuunjukkan hubungan positif menandakan bahwa semakin besar investasi perusahaan terhadap modal intelektualnya maka kinerja perusahaan yang tercermin melalui ROA akan semakin meningkat sehingga hal ini menunjukkan bahwa modal intelektual memberikan nilai tambah pada perusahaan. Semakin baik modal intelektual di suatu perusahaan diolah maka akan membantu perusahaan untuk meminimalkan biaya yang perlu dikeluarkan karena perusahaan dapat menjalankan usahanya secara efisien sehingga dengan minimnya biaya yang perlu dikeluarkan dapat meningkatkan penghasilan perusahaan. Tidak hanya tenaga kerja perusahaan saja yang perlu diperhatikan, namun hubungan antara perusahaan dengan pihak luar dan struktur perusahaan tersebut juga harus diperhatikan.

Hipotesis yang kedua menunjukkan bahwa Ha yang diterima dimana pengungkapan corporate social responsibility berpengaruh signifikan positif terhadap return on assets, maka hasil penelitian ini konsisten dengan penelitian yang telah dilakukan oleh Agustina, Yuniarta, dan Sinarwati (2015) serta Sari dan Suaryana (2013) yang dimana juga melakukan penelitian mengenai hubungan antara pengungkapan CSR dengan kinerja perusahaan dan memiliki hasil bahwa pengungkapan CSR berpengaruh signifikan positif terhadap kinerja perusahaan. Selain itu, berdasarkan teori menuruut Gray et al (1998) dalam Wardani (2015 ) terdapat beberapa tujuan dari pengungkapan tanggung jawab sosial perusahaan yang tela h dilakukan, yaitu untuk meningkatkan image perusahaan, akuntabilitas suatu organisasi,, serta menyajikan informasi kepada pihak lain. Dengan meningkatnya image perusahaan yang baik dimata publik atas kegiatan CSR ya ng telah dilakukan, maka akan mendorong perusahaan tersebut untuk lebih dikenal oleh mas yarakat luas karena keikutsertaannya kedalam bidang sosial dan kemasyarakatan sehingga hal ini akan mendorong masyarakat untuk membeli produk yang ditawarkan oleh perusahaan yang bersangkutan dikarenakan telah me ngenal perusahaan tersebut dan dengan demikian dapat meningkatkan penjualan perusahaan karena produk yang dihasilkan laku dipasaran sehingga akan berujung pada peningkatan profitabilitas. Selain itu perusahaan yang melakukan kegiatan CSR juga akan lebih dipercaya di banding perusahaan lainnya karena masyarakat telah mengenal perusahaan tersebut dengan baik sehingga produk yang ditawarkan oleh perusahaan yang bersangkutan lebih dipercaya dibanding produk dari pesaingnya. 
Aktivitas CSR serta $\mathrm{p}$ engungkapan yang telah dilakukan dapat $\mathrm{m}$ eningkatkan kinerja perusahaan karena perusahaan yang telah melakukan aktivitas CSR akan memiliki citra yang baik di mata publik dan akan lebih dipercaya sehingga dapat mendorong masyarakat untuk menggunakan produk yang ditawarkan. Tidak hanya itu, perusahaan juga dapat meningkatkan kemampuan dari pegawai kar ena pegawai yang berkompeten mampu me njalankan kegiatan operasional secara efektif dan efisien. Maka dari itu, berdasarkan hasil analisis hipotesis kedua dapat dilihat bahwa semakin banyak kegiatan CSR yang diungkapkan maka akan meningkatkan citra dari perusahaan tersebut yang dapat berujung kepada peningkatkan kinerja perusahaan dimana da pat dilihat pada meningkatnya profitabilitas perusahaan (return on assets).

\section{SIMPULAN, KETERBATASAN DAN SARAN \\ 5.1. Simpulan}

Hasil penelitian ini menunjukkan bahwa modal intelektual berpengaruh secara signifikan positif terhadap kinerja perusahaan. Hubungan yang signifikan positif dapat terjadi karena dengan adanya modal intelektual yang diolah dan dikembangkan dengan baik seperti memberikan gaji yang sesuai dengan pekerjaannya serta tunjangan kepada pegawai dapat memberikan nilai tambah dimana pegawai akan bekerja dengan sungguh-sungguh dan termotivasi sehingga pekerjaan dapat dijalankan secara efisien dan efektif dimana dapat menekan biaya-biaya lainnya dan meningkatkan laba perusahaan.

Hasil penelitian ini jug a mengindikasikan bahwa pengungkapan tan ggung jawab sosial perusahaan (CSRD) berpenga ruhsecara signifikan positif terhadap kinerja perusahaan yang diproksikan dengan return on assets. Hal ini terjadi karena den gan dilakukannya pengungkapan CSR dapat meningkatkan kepercayaan publik dan m eningkatkan image perusahaan sehingga masyarakat akan tertarik dengan produk yang ditawarkan perusahaan karena lebih terpercaya sehingga dapat meningkatkan kinerja perusahaan.

\subsection{Keterbatasan}

1. Pengukuran human $\mathrm{c}$ apital pada VAIC masih sangat sederh ana karena hanya menggunakan biaya gaji dan tunjangan saja sebagai indikator dalam perhitungan human capital, sementara untuk meningkatkan produktivitas para tenaga kerjanya masih ada biaya-biaya lain yang dikeluarkan seperti biaya pelatihan.

2. Penelitian ini juga hany a membandingkan CSRD dan IC pada tahun-n terhadap ROA tahun$\mathrm{n}$, sementara kegiatan CSR dan pengembangan IC juga dapat berpengaruh ketahun-tahun berikutnya.

\subsection{Saran Penelitian Selanjutnya}

Adapun saran untuk penelitian selanjutnya :

1. Dapat menambahkan indikator lainnya dalam mengukur human capital pada VAIC seperti biaya yang dikeluarkan dalam rangka meningkatkan keterampilan dan kemampuan sumber daya manusia sehingga nilai yang tercipta dari human capital dapat tergambarkan lebih jelas .

2. Penelitian berikutnya juga dapat menguji pengaruh CSRD dan IC terhadap kinerja perusahaan dengan lag 1-2 tahun karena ada kemungkinan bahwa kegiatan yang dikembangkan saat tahun dapat berdampak ke tahun-tahun berikutnya. 


\section{DAFTAR PUSTAKA}

Agustina, W., Yuniarta, G. A., \& Sinarwati, N. K. (2015). Pengaruh Intelectual Capital, Corporate Social Res ponsibility dan Good Corporate Governance terhadap Kinerja Keuangan. E-Journal S1 Ak Universitas Pendidikan Ganesha, 3 (1). Retrieved April 30,2017 , from

http://www.academia.edu/20318261/Pengaruh_Intelectual_Capital_Csr_Dan_ Gcg_Terhadap_Kinerja_Keuangan_Perusahaan.

Alipour, M. (2012). The Effecct of Intellectual Capital on Firm Performance: An Investigation of Iran Insurance Companies. Measuring Business Exc ellence, 16 (1). doi:10.1108/13683041211204671.

Barkemeyer, R. (2007). Legitimacy as a Key Driver and Determinant of CSR in Developing Countries. Retrie ved April 30, 2017, from

https://www.researchgate.net/publication/228745301_Legitimacy_as_a_key_ driver_and_determinant_of_CSR_in_developing_countries.

Bruggen, A., Vergauwen, P., \& Dao, M. (2009). Determinants of intellectual capital disclosure: evidence from Australia. Management Decision, 47 (2). doi:10.1108/00251740910938894.

Cheng, M., \& Christiawan , Y. J. (2011). Pengaruh Pengungkapan Corporate Social Responsibility terhadap Abnormal Return. Jurnal Akuntansi dan Keuangan, 13 (1). Retrieved April 30, 2017, from

http://jurnalakuntansi.p etra.ac.id/index.php/aku/article/view/18236/18104.

Ciptaningsih, T. (2013). Uji Pengaruh Modal Intelektual terhadap Kinerja Keuangan BUMN yang Go Public di Indonesia. Jurnal Manajemen Teknologi, 12. Retrieved April 30, 2017, from

http://journal.sbm.itb.ac.id/index.php/mantek/article/download/484/683,

Deegan, C. (2014). Financial Accounting Theory 4E. North Ryde, N.S.W: McGraw-Hill.

Dela, F. M. (2014). Pengaruh Ukuran Perusahaan dan Kinerja Lingkungan terhadap Pengungkapan Tanggung Jawab Sosial Perusahaan. Jurnal Akuntansi, 2 (3). Retrieved April 30, 2017, from http://ejournal.unp.ac.id/students/index.php/akt/article/view/1570/1193.

Ermawati. (2014). Pengaruh Corporate Social Responsibility terhadap Kinerja Keuangan Perusahaan pada Peru sahaan Manufaktur yang Terdaftar di Bursa Efek Indonesia. Retrieved 30 April, 2017, from http://eprints.ums.ac.id/30343/13/NASKAH_PUBLIKASI_ILMIA H.pdf.

Fadri, Z., \& Wahidahwati. ( 2016). Pengaruh Intelektual Capital terhada p Profitabilitas dan Produktivitas pada Per bankan Syariah di Indonesia. Jurnal Ilmu \& Riset Akuntansi, 5 (11). Retrieved April 30, 2017, from https://ejournal.stiesia.ac.id/jira/article/view/2556.

Faradina, I., \& Gayatri. (2 016). Pengaruh Intellectual Capital dan I ntellectual Capital Disclosure terhadap Kinerja Keuangan Perusahaan. E-Jurnal Akuntansi Universitas Udayana, 15. Retrieved April 30, 2017, from 
http://id.portalgaruda.org/article.php?article $=458272 \&$ val $=986$

Fatima, H. (2012). Analisis Pengaruh Modal Intelektual terhadap Kinerja Perusahaan di Indonesia. Retrieved A pril 30, 2017, from

http://ib.ui.ac.id/file?file =digital/20315024-S-Hasna\%20Fatima.pd f

Finch, N. (2005). The Motivations for Adopting Sustainability Disclosure [Abstract].

Retrieved April 30, 2017, from

https://www.researchgate.net/publication/228311153_The_Motivations_for_Adoptin g_Sustaina bility_Disclosure.

Global Reporting Initiative. (2013). GRI G4 - Bahasa Indonesia Pedoman Pelaporan Berkelanjutan.

Hadi, N. (2009). Social Responsibility: Kajian Theoretical Framework dan Perannya dalam Riset Dibidang Akunttansi. Jurnal Ekonomi dan Bisnis, 4 (8). Retrieved April 30, 2017, from https://publikasiilmiah.unwahas.ac.id/index.php/AKSES/article/view/517/639.

Hadiwijaya, R. C., \& Rohm an, A. (2013). Pengaruh Intellectual Capital terhadap Nilai Perusahaan dengan $\mathrm{K}$ inerja Keuangan sebagai Variabel Interv ening. Diponegoro Journal Of Accounti ng, 2 (3). Retrieved April 30, 2017, from

http://ejournal-s1.undip.ac.id/index.phhp/accounting. ISO. (2010). ISO 26000: Guid ance on Social Responsibility.

Prasetio, F. (2015). Pengaru h Intellectual Capital terhadap Kinerja Keu angan Perusahaan. Retrieved April 30, 20 17, from

http://eprints. undip.ac.id/45699/1/06_PRASETIO.pdf.

Pulic, A. (1998). Measuring T he Performance of Intellectual Capital in Knowledge Economy. Retrieved April 30, 2017, from https://xa.yimg .com/kq/groups/21741988/1414311172/name/pulic 1998.pdf.

Sari, N. K., \& Suaryana, I. G. (2013). Pengaruh Pengungkapan CSR terhadap Kinerja Keuangan dengan Kepemilikan Asing sebagai Variabel Mod erator. EJuR, 3. Retrieved May 1, 2017, from

http://download.portalgaruda. org/article.php?article $==82210 \& v a l=986$.

Undang-undang Republik Indonesia Nomor 40 Tahun 2007 Pasal 74 tentang Perseroan Terbatas. (2007). Retrieved April 30, 2017, from http://www.hukumonline.com/pusatdata/downloadfile/fl52313/parent/26940.

Wardani, M. K. (2015). Pengaruh Pengungkapan Corporate Social Responsibility terhadap Profitabilitas Peru sahaan. Retrieved April 30, 2017, from https://repository.usd.ac.id/995/2/112114019_full.pdf.

Wijayanti, R. (2016). Pengaruh Pengungkapan Sustainability Report terhadap Kinerja Keuangan Perusahaan. Retrieved April 30, 2017, from https://publikasiilmiah.ums.ac.id/handle/11617/7350. 


\section{LAMPIRAN}

Variabel Independen

Variabel Dependen

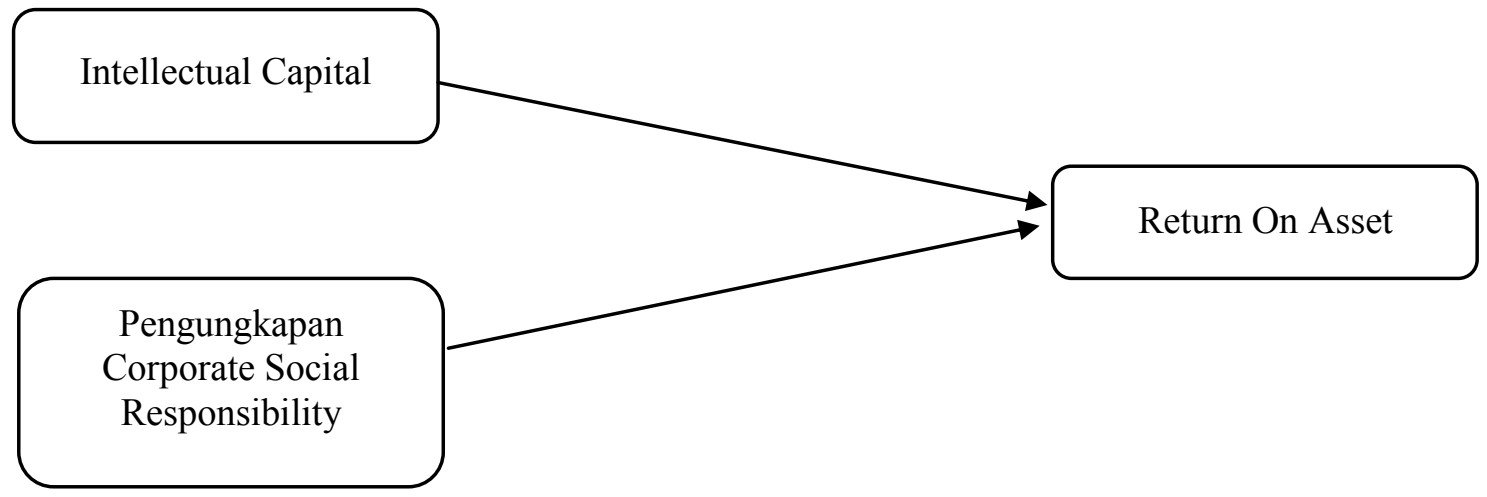

Gambar 1. Model Kerangka Pemikiran

Tabel 1. Proses Pemilihan Sampel

\section{Keterangan}

Jumlah

Populasi meliputi jumlah lap oran tahunan lengkap perusahaan manufaktur sektor 232 industri da sar dan kimia yang terdaftar di BEI selama tahun 2013 - 2016

Jumlah laporan tahunan yang tidak disajikan selama periode 2013 - 2016

Jumlah laporan keuangan per usahaan yang memiliki laba dan ekuitas negative

Jumlah laporan keuangan per usahaan dalam mata uang asing

\section{Jumlah Sampel Akhir}

Sumber : Bursa Efek Indonesia (BEI)

Tabel 2. Statistik Deskriptif

\begin{tabular}{ccccccc} 
& ROA & VAIC & CSR & FS & LEV & CI \\
\hline Mean & 0.0726 & 5.5241 & 0.2302 & 14.5664 & 0.9974 & 1.4956 \\
\hline Maximum & 0.2607 & 18.9262 & 0.4396 & 17.6408 & 6.3400 & 16.2642 \\
\hline Minimum & 0.0060 & 2.2102 & 0.1209 & 11.8215 & 0.0018 & 0.4752 \\
\hline Std. Dev. & 0.0544 & 2.9573 & 0.0871 & 1.6171 & 1.2332 & 1.8512 \\
\hline Observation & 76 & 76 & 76 & 76 & 76 & 76
\end{tabular}

Sumber : Hasil Pengolahan Data dengan software Eviews 7 
Tabel 3. Hasil Uji Normalitas (Setelah di Log)

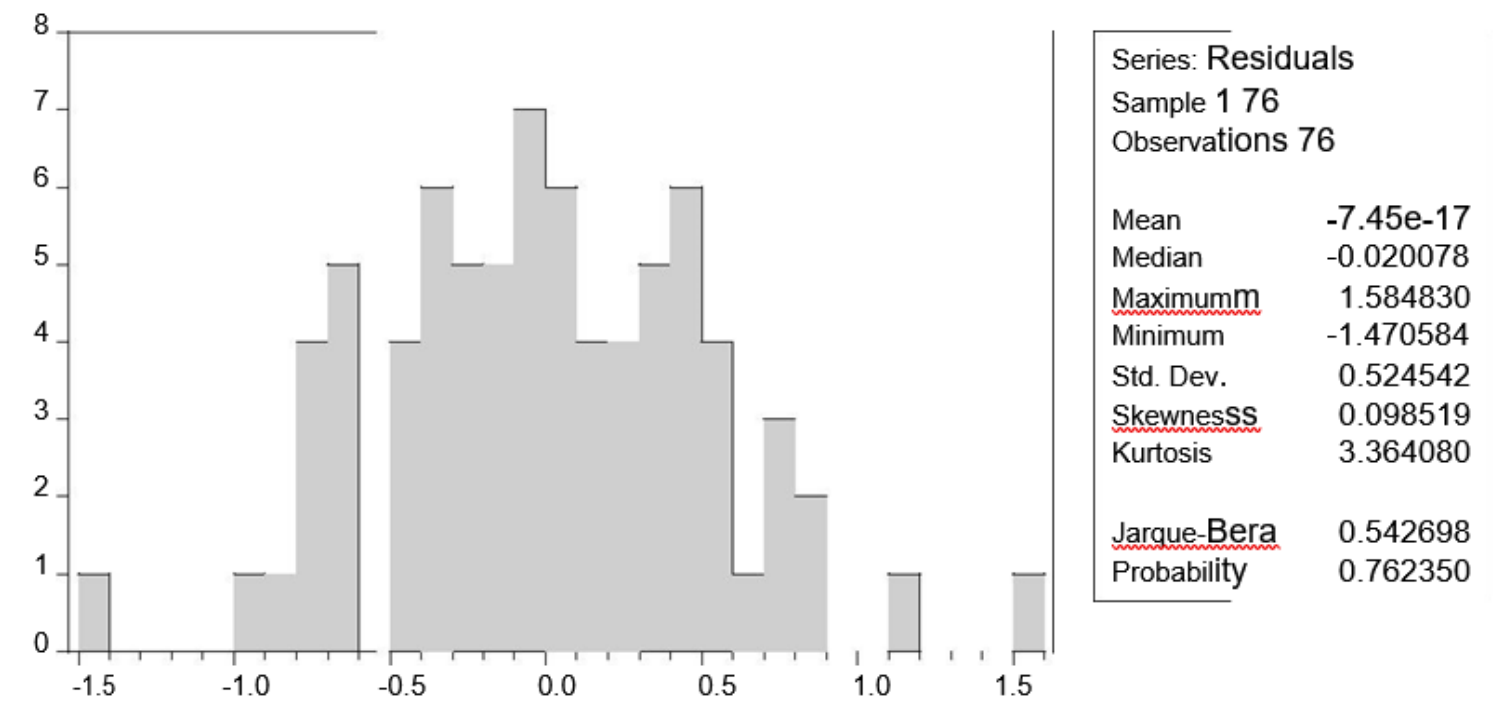

Sumber : Hasil Pengolahan Data dengan software Eviews 7

Tabel 4. Hasil Uji Multikolinearitas (Correlation Matrix)

\begin{tabular}{cccccc} 
& VAIC & CSR & FS & LEV & LO G(CI) \\
\hline VAIC & 1.0000 & 0.5574 & 0.5352 & -0.2550 & -0.0277 \\
\hline CSR & 0.5574 & 1.0000 & 0.5658 & -0.3735 & 0.1270 \\
\hline FS & 0.5352 & 0.5658 & 1.0000 & -0.0207 & 0.0463 \\
\hline LEV & -0.2550 & -0.3735 & -0.0207 & 1.0000 & -0.0910 \\
\hline LOG(CI) & -0.0277 & 0.1270 & 0.0463 & -0.0910 & 1.0000
\end{tabular}

Sumber : Hasil Pengolahan Data dengan software Eviews 7

Tabel 5. Hasil Uji Multikolinearitas (VIF)

\begin{tabular}{cc} 
Variable & Centered VIF \\
\hline C & NA \\
\hline VAIC & 1.6823 \\
\hline CSR & 2.0044 \\
\hline FS & 1.7852 \\
\hline LEV & 1.2734 \\
\hline LOG $(\mathrm{CI})$ & 1.0349
\end{tabular}

Sumber : Hasil Pengolahan Data dengan software Eviews 7

Tabel 6. Hasil Uji Heteroske Dastisitas

Heteroskesdasticity Test: White

\begin{tabular}{llll}
\hline F-Statistic & 0.9069 & Prob. F(20,55) & 0.5804 \\
\hline Obs*R-squared & 18.8482 & Prob. Chi-Square(20) & 0.5317 \\
\hline Scaled explained SS & 18.9004 & Prob. Chi-Square(20) & 0.5283 \\
Sumber : Hasil Pengolahan Data dengan software Eviews 7 &
\end{tabular}


Tabel 7. Hasil Regresi

Dependent Variable: LOG(ROA)

\begin{tabular}{lrcrc}
\hline \multicolumn{5}{c}{ Method: Least Squares } \\
\hline \multicolumn{5}{c}{ Sample: 1 76 } \\
\hline \multicolumn{5}{c}{ Include Observations: 76 } \\
\hline Cariable & Coefficient & Std. Error & t-Statistic & Prob. \\
\hline VAIC & -2.0133 & 0.6215 & -3.2397 & 0.0018 \\
\hline CSR & 0.1342 & 0.0275 & 4.8788 & 0.0000 \\
\hline FS & 4.6528 & 1.0186 & 4.5677 & 0.0000 \\
\hline LEV & -0.1714 & 0.0518 & -3.3087 & 0.0015 \\
\hline LOG(CI) & -0.2179 & 0.0574 & -3.7982 & 0.0003 \\
\hline R-squared & -0.2680 & 0.1117 & -2.3992 & 0.0191 \\
\hline Adjusted R-squared & 0.6647 & Mean dependent var & -2.9618 \\
\hline S.E. of regression & 0.6407 & S.D. dependent var & 0.9058 \\
\hline Sum squared resid & 0.5430 & Akaike info criterion & 1.6921 \\
\hline Log likehood & 20.6359 & Schwarz criterion & 1.8761 \\
\hline F-statistic & -58.2986 & Hannan-Quinn criter & 1.7656 \\
\hline Prob(F-statistic) & 27.7501 & Durbin-Watson stat & 1.0523 \\
\hline
\end{tabular}

Sumber : Hasil Pengolahan Data dengan software Eviews 7 